\section{Correction of}

\section{Cerebrospinal Fluid Copper in Menkes Kinky Hair Disease}

\author{
Peter R. Kollros, MD, PhD*ं, \\ Robert D. Dick, BS ${ }^{\ddagger}$, and \\ George J. Brewer, $\mathrm{MD} \ddagger \S$
}

A patient with Menkes Kinky Hair disease was treated with infusions of copper-histidine which resulted in normal copper values in the cerebrospinal fluid. This tends to confirm the in vitro data that copper is transported into the central nervous system complexed with histidine or other similar ligands.

Kollros PR, Dick RD, Brewer GJ. Correction of cerebrospinal fluid copper in Menkes kinky hair disease. Pediatr Neurol 1991;7:305-7.

\section{Introduction}

Menkes kinky hair disease (MKHD) is a disorder of impaired dietary copper absorption and abnormal copper distribution $[1,2]$. Patients present with severe developmental retardation, hypotonia, seizures, and abnormalities of connective tissues and blood vessels. Prior treatments have focused on correcting the systemic copper deficiency. Intravenous administration of inorganic copper salts failed to normalize central nervous system (CNS) copper measured in the cerebrospinal fluid (CSF) [3,4] (personal communication). Similarly, correction of neurodevelopmental deficiencies has been unsuccessful in the classic, severe form of this disease [5]. This report documents the intravenous infusion of copper-histidine with the correction of CSF copper to normal values in a patient with MKHD.

\section{Case Report}

A 20-week-old male presented with new-onset respiratory difficulty and seizures. He had episodes of fine upper extremity tremors and apnea. His parents reported that he smiled, cooed, and could follow objects with his eyes, but was unable to reach, grasp, or roll over.

The examination revealed a lethargic, extremely hypotonic, pale, caucasian infant with scaly skin. The scalp felt like fine sand paper due to the short broken hairs and microscopic examination revealed characteristic pili torti of MKHD. Head control was extremely poor and the child slipped through the examiner's hands on vertical suspension. Skull radiography revealed wormian bones. Plasma copper was $23 \mathrm{mg} / \mathrm{dl}$ (normal: $70-130 \mathrm{mg} / \mathrm{dl}$ ), ceruloplasmin $1.5 \mathrm{mg} / \mathrm{dl}$ (normal: $15-35 \mathrm{mg} / \mathrm{dl}$ ), and CSF copper $5 \mathrm{ng} / \mathrm{ml}$ (normal: $12-27 \mathrm{ng} / \mathrm{ml}$ ) [4]. Cultured skin fibroblasts from the patient retained an excess of copper in a pattern indicative of MKHD (personal communication) [6].

After institutional review and parental consent, treatment with 10 $\mathrm{ml} / \mathrm{kg}$ of fresh frozen plasma (FFP) immediately followed by intravenous copper-histidine was initiated. Each treatment contained $3.6 \mathrm{mg}$ of cupric acetate monohydrate, $8.0 \mathrm{mg}$ of histidine hydrochloride monohydrate, adjusted to $\mathrm{pH} 7.0,10 \mathrm{cc}$ in volume and normal saline salt concentration providing $1.2 \mathrm{mg}$ of elemental copper in a molar ratio of copper/histidine of $1 / 2$. The copper-histidine solution was filtered for sterility, added to $20 \mathrm{cc}$ of normal saline, and infused over 1 hour. The patient exhibited no side effects except for sclerosis of the veins. The parents reported that approximately 6 hours after infusions the patient was fussier than usual. Broviac ${ }^{\circledR}$ catheter placement solved intravenous access difficulties. Therapy was monitored by serial serum ceruloplasmin, plasma copper, plasma zinc, and CSF copper measured by flame and flameless atomic absorption spectrometry. All samples were drawn just prior to giving the next copper dose and therefore represent trough levels.

The patient initially was treated daily with FFP and intravenous copper-histidine until the plasma copper, CSF copper, and ceruloplasmin normalized. The child then received weekly therapy with FFP and copper-histidine. The ceruloplasmin, plasma copper, and CSF copper all declined, and a short period of daily treatment was reinstituted until values normalized (Figs 1-3). Again weekly parenteral FFP and copperhistidine was instituted, but this time was supplemented with daily oral copper-histidine, the same solution used above but without the final $20 \mathrm{cc}$ dilution. The oral dose was adjusted occasionally but was given to a maximum of $2 \mathrm{cc} 3$ times daily (elemental copper $0.72 \mathrm{mg} /$ day orally). The combination of weekly parenteral and 3 times daily oral therapy maintained plasma and CSF copper levels in the normal range. On one testing an elevated CSF copper level was obtained which was associated with an elevated serum copper value. No abnormalities in liver or kidney function tests resulted from the treatment. The plasma zinc concentrations fluctuated greatly, but elevated copper concentrations did not consistently suppress plasma zinc concentrations.

At 13 months of age our patient exhibited no neurodevelopmental gains with therapy. A Bayley test demonstrated that the child's abilities were the same as at the time of his diagnosis and placed the child's development at 1 month of age. Treatments with FFP were stopped to avoid the risks of transfusion-acquired disease, but weekly parenteral copper and daily oral copper therapy continued. Twelve weeks after FFP transfusions were discontinued plasma copper levels remained within the normal range and the CSF copper decreased to the normal range.

\section{Discussion}

The primary biochemical abnormalities in MKHD have been related to abnormal copper binding and defective copper transport at the intestine and the blood-brain barrier. CNS manifestations of the disease may be related to dysfunction of the copper-requiring enzymes cytochrome c [5] and dopamine $\beta$-hydroxylase [7]. Transport of copper into the CNS has been studied using rat hypothalamic
From the Departments of *Pediatrics, ${ }^{\dagger}$ Neurology, ${ }^{\ddagger}$ Human Genetics, and ${ }^{\delta}$ Internal Medicine; University of Michigan Medical Center; Ann Arbor, Michigan.
Communications should be addressed to:

Dr. Kollros; Department of Pediatrics; Jefferson Medical College;

Room 700 College Building; 1025 Walnut Street;

Philadelphia, PA 19107-5083.

Received November 9, 1990; accepted February 8, 1991. 


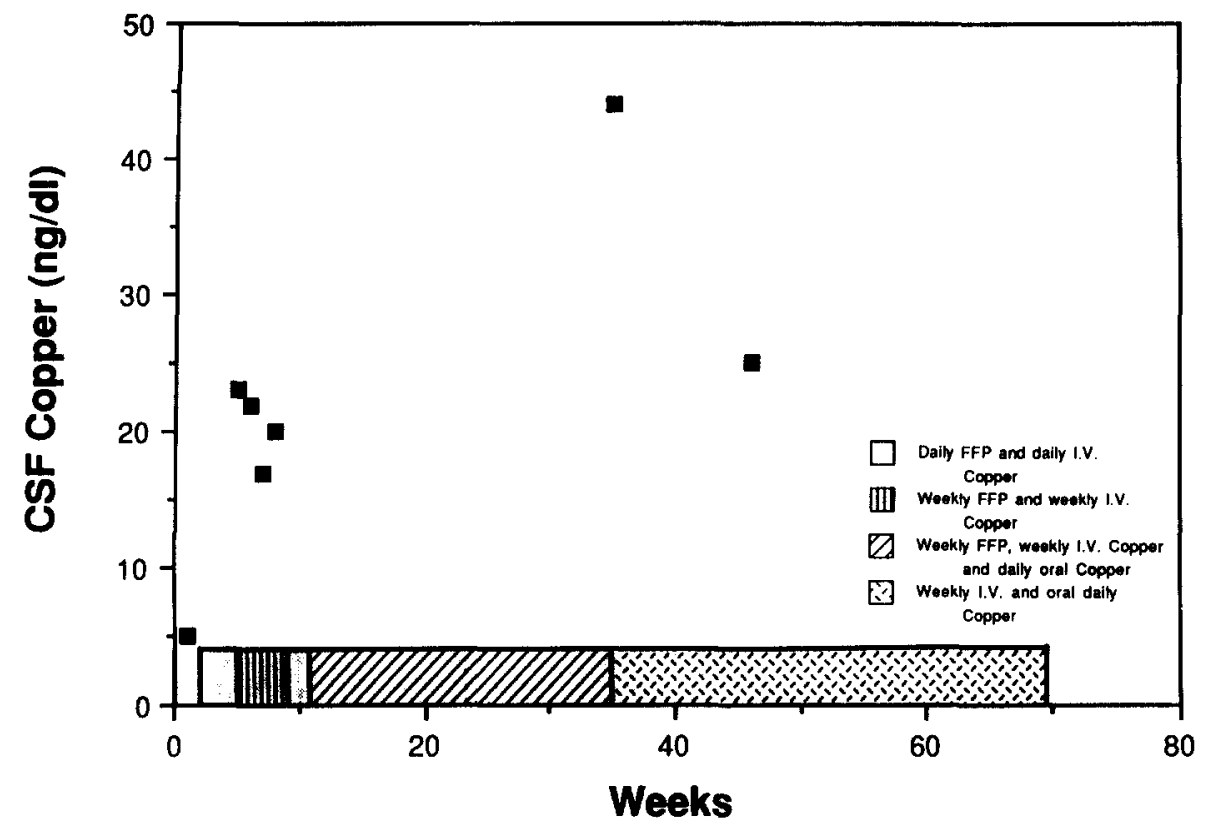

Figure 1. Scattergram of CSF copper concentrations prior to and during therapy.

tissue slices [8]. Two facilitated diffusion processes were elucidated. Both systems had broad ligand specificity with respect to amino acids (i.e., histidine, cysteine, threonine, glycine) and small peptides (Gly-His-Lsy and glutathione) but albumin did not serve as a facilatory ligand. In our patient intravenous administration obviated the need for intestinal copper absorption. The plasma and CSF copper values closely paralleled each other, confirming that copper was provided in a form that could be transported in the CNS.

Pretreatment with FFP prior to the infusion of copperhistidine, when performed weekly over a period of months, resulted in a CSF copper value of approximately
2 times normal. When the FFP pretreatment was discontinued the CSF copper decreased to normal values. This limited observation raises the possibility that there may be a factor in FFP that further facilitates copper accumulation into the CNS.

The relationship between CSF and brain copper in this disease has not been reported and would require brain biopsies to determine it; however, in Wilson disease there is a relationship between CSF copper, treatment, and clinical improvement which presumably is related to a decline in brain copper [9].

Our patient should be compared with other MKHD patients. Although the reports of CSF copper are scattered,

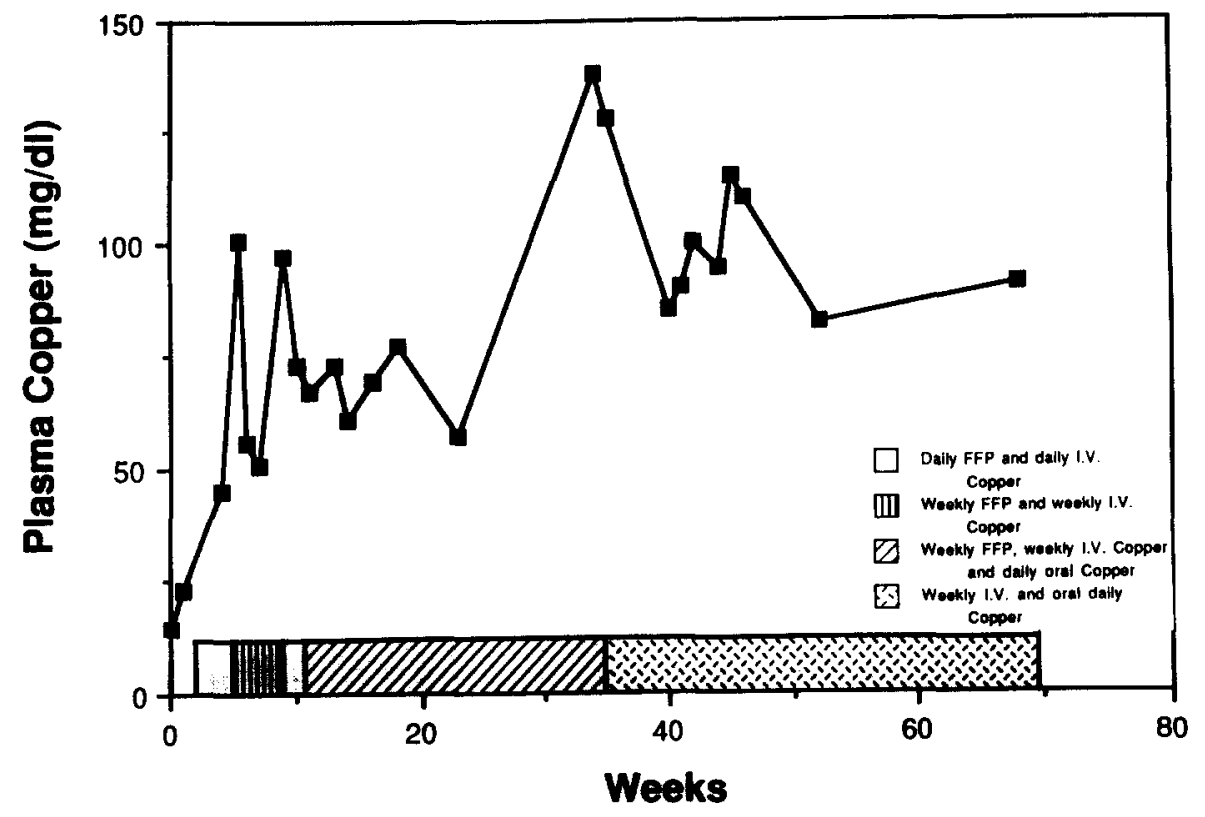

Figure 2. Plasma copper concentrations obtained prior to and during therapy. 


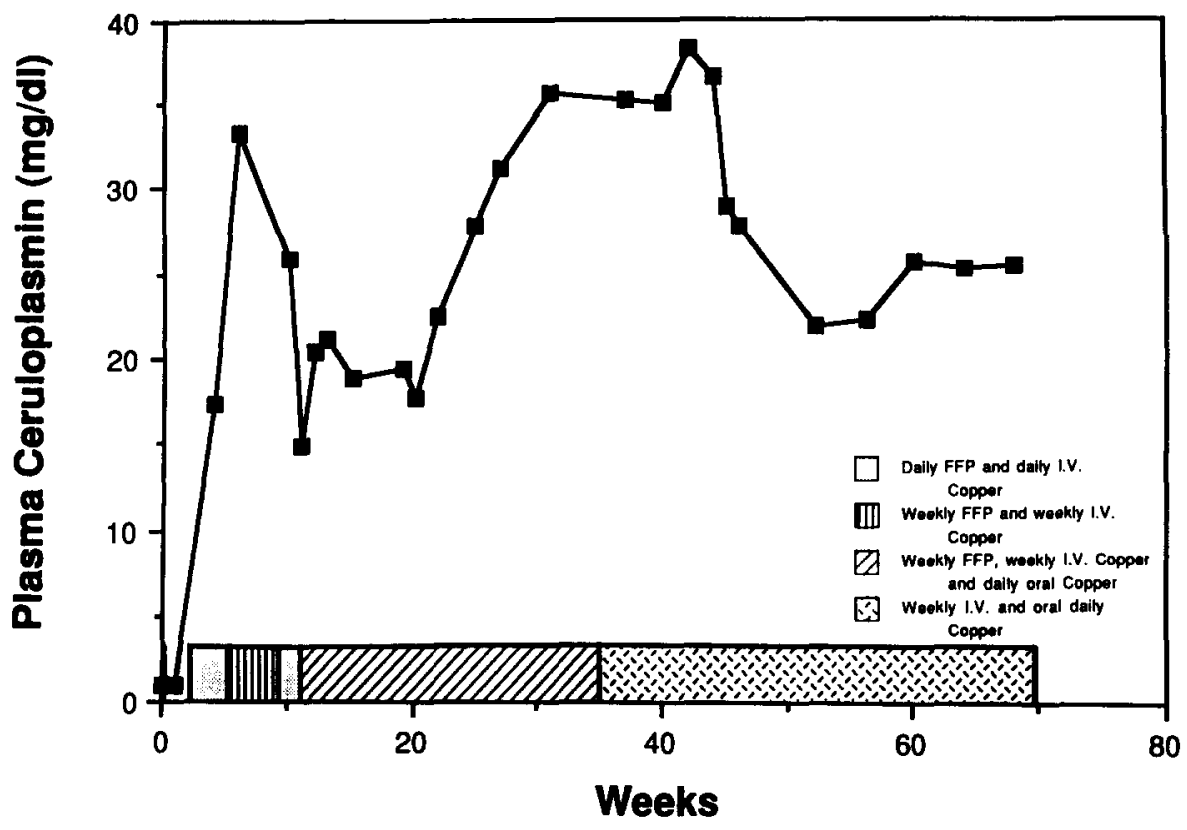

Figure 3. Plasma ceruloplasmin concentrations prior to and during therapy.

correction of CSF copper with copper sulfate therapy has generally failed and high normal and elevated values have not been reported even with higher dose equivalents of elemental copper $[3,4]$ (personal communication). In contrast to 2 patients treated with subcutaneous copper-histidine injections, our patient did not make neurodevelopmental progress [10]. Perhaps our treatment was begun too late in development, after a critical period, so that the child was unable to recover. Alternatively, there may be genetic heterogeneity in MKHD such that some patients are unable to respond to copper-histidine therapy; therefore, although copper reaches the CNS, normal neurodevelopment may not occur because the patient may be unable to correctly utilize the copper. Genetic heterogeneity governing the response to a different type of MKHD therapy has been reported [4].

We thank Drs. Gary W. Goldstein and Warren Grover for their constructive input in this project, Jennifer Smith for her care of the patient and collection of samples, and Dr. Gary Carpenter for critical reading of the manuscript.

Work on this project was done in part during the tenure of a ClinicianScientist Award from the American Heart Association to Dr. Kollros.

\section{References}

[1] Danks DM. Of mice and men, metal and mutations. J Med Genet 1986;23:99-106.

[2] McKusick VA. Mendelian inheritance in man, 8th ed. Baltimore: Johns Hopkins University Press, 1988;1338-40.

[3] de Groot CJ, Wijburg FA, Barth PG, et al. Vitamin C treatment of Menkes disease: Failure to affect biochemical and clinical parameters. J Inherited Metab Dis 1989;12(Suppl 2):389-92.

[4] Grover WD, Henkin RI, Schwartz M, Brodsky N, Hobdell E, Stolk JM. A defect in catecholamine metabolism in kinky-hair disease. Ann Neurol 1982;12:263-6.

[5] Garnica AD. The failure of parenteral copper therapy in Menkes kinky hair syndrome. Eur J Pediatr 1984;142:98-104.

[6] Beratis NG, Price P, LaBadie G, Hirschhorn K. ${ }^{64} \mathrm{Cu}$ metabolism in Menkes and normal cultured skin fibroblasts. Pediatr Res 1978; 12:699-702.

[7] Butler IJ, Seifert WE, Koslow SH, Caprioli RM, Singer HS. Neurotransmitters in neurological disease of childhood. In: Usdin B, Kopin IJ, Barchap J, eds. Catecholamines: Basic and clinical frontiers. Proceedings of the International Catecholamine Symposium. New York: Pergamon, 1979;1578-80.

[8] Hartter DE, Barnea A. Brain tissue accumulates ${ }^{64}$ copper by two ligand-dependent saturable processes. J Biol Chem 1988;263: 799-805.

[9] Weisner B, Hartard C, Dieu C. CSF copper concentration: A new parameter for diagnosis and monitoring therapy of Wilson's disease with cerebral manifestation. J Neurol Sci 1987;79:229-37.

[10] Sherwood G, Srakar B, Kortsak AS. Copper histidinate therapy in Menkes disease: Prevention of progressive neurodegeneration. $J$ Inherited Metab Dis 1989;12(Suppl 2):393-6. 